\title{
Scrap and Build for Functional Neural Circuits: Spatiotemporal Regulation of Dendrite Degeneration and Regeneration in Neural Development and Disease
}

\author{
Kotaro Furusawa ${ }^{1}$ and Kazuo Emoto ${ }^{1,2 *}$ \\ ${ }^{1}$ Department of Biological Sciences, Graduate School of Science, The University of Tokyo, Tokyo, Japan, ${ }^{2}$ International \\ Research Center for Neurointelligence (WPI-IRCN), The University of Tokyo, Tokyo, Japan
}

\section{OPEN ACCESS}

Edited by:

Quan Yuan

National Institute of Neurological Disorders and Stroke (NINDS),

United States

Reviewed by:

Fernando Vonhoff

University of Maryland, United States

Cheng-Ting Chien,

Academia Sinica, Taiwan

*Correspondence:

Kazuo Emoto

emoto@bs.s.u-tokyo.ac.jp

Specialty section: This article was submitted to

Cellular Neurophysiology,

a section of the journal

Frontiers in Cellular Neuroscience

Received: 02 October 2020 Accepted: 04 December 2020

Published: 11 January 2021

\section{Citation:}

Furusawa K and Emoto $K$ (2021) Scrap and Build for Functional Neural Circuits: Spatiotemporal Regulation of Dendrite Degeneration and Regeneration in Neural

Development and Disease.

Front. Cell. Neurosci. 14:613320. doi: 10.3389/fncel.2020.613320
Dendrites are cellular structures essential for the integration of neuronal information. These elegant but complex structures are highly patterned across the nervous system but vary tremendously in their size and fine architecture, each designed to best serve specific computations within their networks. Recent in vivo imaging studies reveal that the development of mature dendrite arbors in many cases involves extensive remodeling achieved through a precisely orchestrated interplay of growth, degeneration, and regeneration of dendritic branches. Both degeneration and regeneration of dendritic branches involve precise spatiotemporal regulation for the proper wiring of functional networks. In particular, dendrite degeneration must be targeted in a compartmentalized manner to avoid neuronal death. Dysregulation of these developmental processes, in particular dendrite degeneration, is associated with certain types of pathology, injury, and aging. In this article, we review recent progress in our understanding of dendrite degeneration and regeneration, focusing on molecular and cellular mechanisms underlying spatiotemporal control of dendrite remodeling in neural development. We further discuss how developmental dendrite degeneration and regeneration are molecularly and functionally related to dendrite remodeling in pathology, disease, and aging.

Keywords: dendrite, remodeling and dysfunction, morphogenesis, development, repair

\section{INTRODUCTION}

Dendrites are specialized structures designed to receive information from presynaptic neurons or sensory organs. During postnatal development of the mammalian brain, neurons exhibit extensive plasticity in which connectivity can be modified in response to neural inputs and/or hormonal regulation (Parrish et al., 2007a; Jan and Jan, 2010; Emoto, 2011; Batista and Hensch, 2019; 
Molnar et al., 2020). To achieve these changes in connectivity, neurons often remodel their dendrite shape through a combination of degeneration and regeneration of local dendritic branches (Kanamori et al., 2015b; Riccomagno and Kolodkin, 2015). Owing to technical advances in in vivo imaging, researchers are now able to fully trace branch dynamics of single neurons with high spatiotemporal resolution. These in vivo imaging studies have revealed that developing dendrites often undergo multiple rounds of regeneration and regeneration before the establishment of their final shape (Yasunaga et al., 2010; Kaneko et al., 2011; Takeo et al., 2015; Nakazawa et al., 2018).

In addition to developmental dendrite degeneration and regeneration, certain types of neurons remodel their dendritic arbors in response to injury on dendritic branches (Richardson and Shen, 2019; Liu and Jan, 2020). The progression of injury-induced dendrite degeneration and regeneration are morphologically similar to what was observed in developmental dendrite degeneration and regeneration, respectively, suggesting that the developmental and injury-induced remodeling involve a shared program. However, recent studies indicate that regulatory mechanisms of injury-induced dendrite degeneration and regeneration are distinct at least in part from mechanisms governing either developmental dendrite degeneration and regeneration or injury-induced axon degeneration and regeneration (Stone et al., 2014; Thompson-Peer et al., 2016; Hao et al., 2019; Zhu et al., 2019).

In this review article, we first describe an overview of diverse types of dendrite degeneration and regeneration in vertebrates and invertebrates. We then review what is currently known about the molecular and cellular mechanisms underlying dendrite remodeling, focusing on the temporal and spatial control of degeneration and regeneration. We also discuss how developmental dendrite degeneration and regeneration are molecularly and functionally related to dendrite remodeling in pathology, disease, and aging.

\section{DEVELOPMENTAL DENDRITE REMODELING IN VERTEBRATE NEURONS}

Developmental dendrite remodeling is typically achieved by degeneration and regeneration of local dendrite branches. One well-studied system is the dendrite remodeling of mitral cells, the second-order projection neurons in the mammalian olfactory system (Wong and Ghosh, 2002). In the adult olfactory bulb, mitral cells extend a single apical dendrite radially that arborizes a tuft within one glomerulus (Mori and Sakano, 2011; Sakano, 2020). Also, mitral cells extend lateral dendrites that are widely distributed within a horizontal plane in the external plexiform layer and make reciprocal dendrodendritic synapses with granule cells. This mature arborization pattern is the result of extensive refinement: during perinatal development, mitral cells extend dendritic branches to multiple glomeruli, and subsequently, they lose all but one dendritic branch, maintaining contacts with a single glomerulus as they mature (Figure 1A; Mori and Sakano, 2011; Murthy, 2011; Sakano, 2020). This selective dendrite degeneration in mitral cells is critical to fine-tuning olfactory circuits involved in odor processing (Inoue et al., 2018; Fujimoto et al., 2019).

Purkinje cells in the cerebellum typically elaborate spacefilling type dendrites in a single parasagittal plane (Figure 1B), but as in the case of mitral cells, the mature form of Purkinje cell dendrites involves developmentally programmed degeneration and regeneration. Recent in vivo imaging studies have revealed that Purkinje cells establish distinct features of their dendrite arbors including dendrite branch pattern and orientation over multiple cycles of dendrite degeneration and regeneration (Figure 1B). Purkinje cells initially develop multiple dendritic protrusions from the soma, designated as perisomatic dendrites, before birth (Sotelo and Dusart, 2009; Takeo et al., 2015). Next, over 2-3 days Purkinje cells eliminate all perisomatic dendrites. Finally, they regenerate single stem dendritic branches over several weeks. In the course of single stem dendrite development, Purkinje cells initially develop multiplanar dendrites that extend dendritic arbors into a 3D space (Kaneko et al., 2011). However, within the next several days, Purkinje dendritic branches become trimmed and are eventually confined into a single plane (Figure 1B).

During early postnatal development, certain types of pyramidal neurons in the mammalian cortex likewise exhibit highly dynamic rearrangement of dendritic arbors. For example, layer IV pyramidal neurons in the rodent barrel cortex can be divided into two distinct subtypes: the spiny stellate neurons and the star pyramidal neurons (Nakazawa et al., 2018). The spiny stellate neurons on the edge of the barrel predominantly form synaptic contacts with thalamocortical axons (Espinosa et al., 2009; Mizuno et al., 2014; Nakazawa et al., 2018). In vivo two-photon imaging indicates that this organization involves selective degeneration of a subset of nascent dendrites. Spiny stellate neurons typically extend both apical and basal dendrites by postnatal day 2-3 and then retract all of their apical dendrites over the next several days while basal dendrites continue to extend, eventually forming synaptic contacts with the thalamocortical axons (Nakazawa et al., 2018; Figure 1C). Interestingly, the extension of the basal dendrites is biased to the center direction of the barrel, presumably because the thalamocortical axons mainly innervate the central part of the barrel, which recruits the basal dendrites of the spiny stellate neurons (Figure 1C).

A novel type of nerve remodeling is recently reported in the dorsal root ganglion (DRG) neurons, the nociceptors that sense pain and itch (Takahashi et al., 2019). Nociceptors innervate sensory terminals into the epidermis layer and form free-ending connections with epidermal cells in the skin. Intravital imaging in the rodent skin reveals that the nerve ends of nociceptors are highly motile structures that are continuously remodeled by extension, retraction, and pruning (Takahashi et al., 2019; Figure 1D). The pruning of the nerve ends is likely to be vital for the formation and/or maintenance of the epidermis-nerve interaction because the nerve ends overshoot to the superficial epidermal layer in the mouse model of atopic dermatitis, which enhances pain sensation in nociceptors in the atopic dermatitis model mice (Takahashi et al., 2019). 

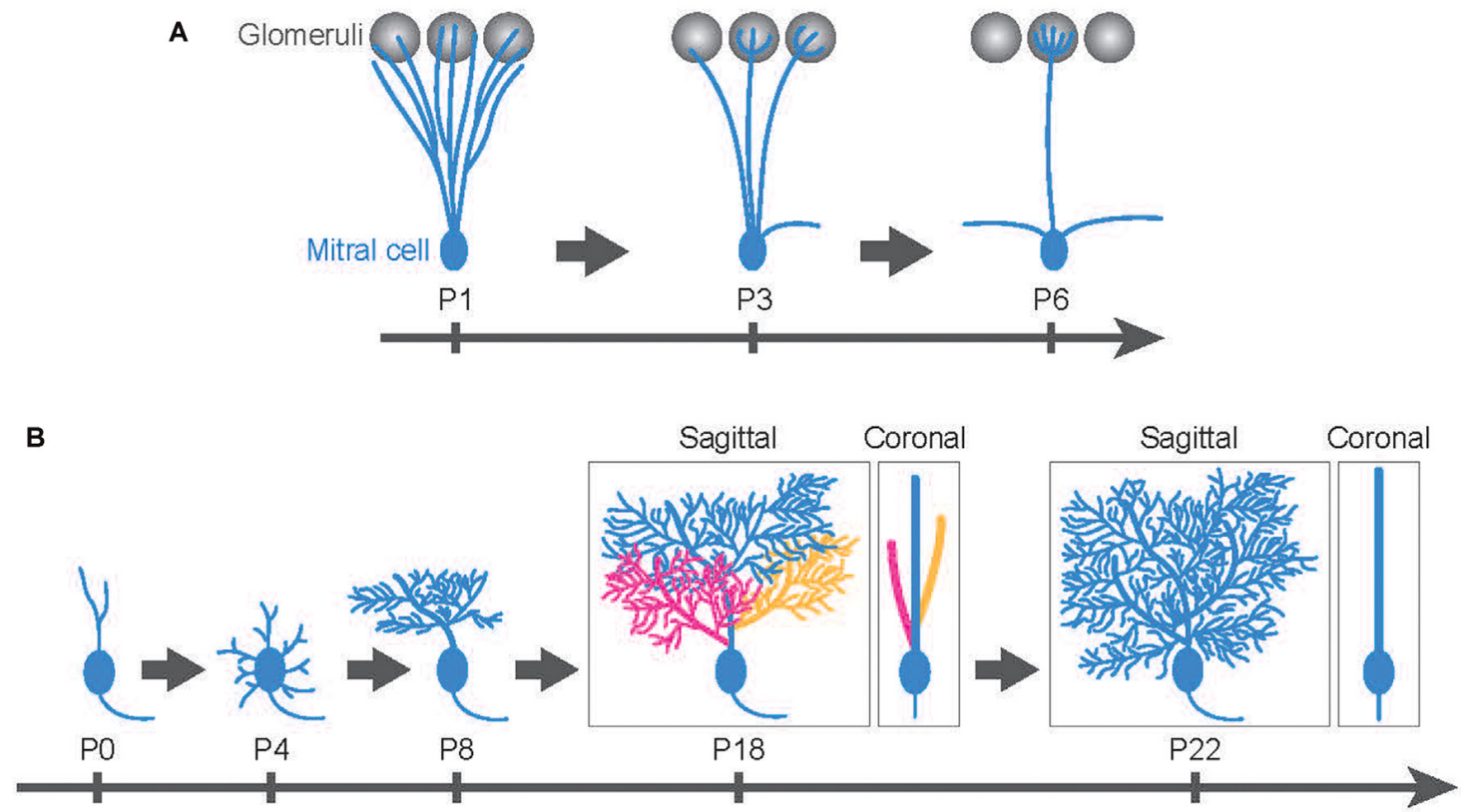

C

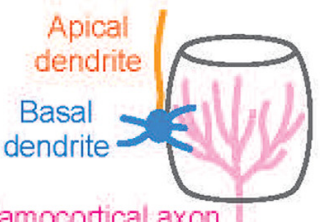

Thalamocortical axon
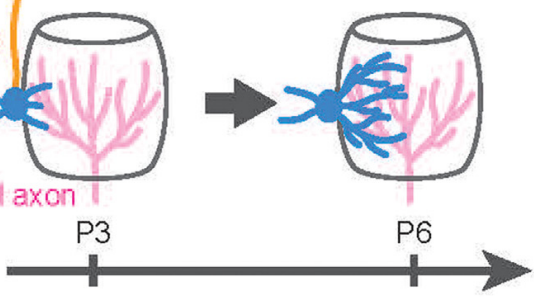

D

E

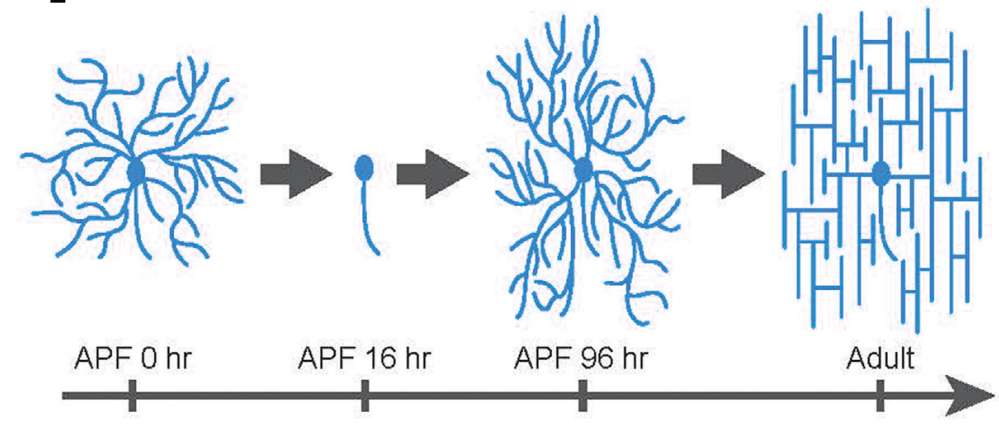

$\mathbf{F}$

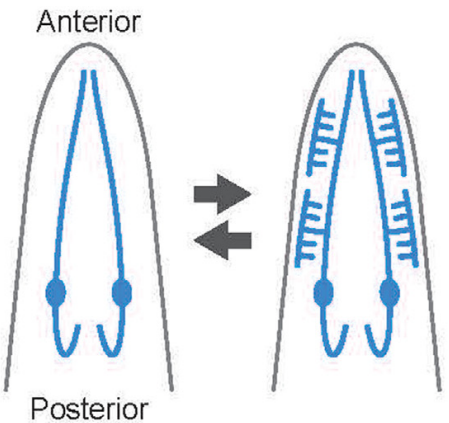

FIGURE 1 | Developmental dendrite remodeling in a variety of neurons. Dendrite remodeling in mitral cells in the murine olfactory system (A), Purkinje cells in the murine cerebellum (B), layer IV pyramidal neurons in the murine somatosensory cortex (C), dorsal root ganglion (DRG) neuron innervating the murine skin (D), Drosophila class IV dendrite arborization (C4da) sensory neurons (E), and C. elegans IL2 sensory neurons (F). (A) Mitral cells initially innervate dendrites (blue) to multiple glomeruli (gray) and later eliminate all but one apical dendrite. (B) Layer IV pyramidal neurons (spiny stellate neurons) initially extend both apical (orange) and basal (blue) dendrites followed by retraction of the apical dendrites while further extending basal dendrites toward thalamocortical axons (magenta). (C) Purkinje cells develop multiple dendritic protrusions from the soma, followed by elimination of the whole branches in the first postnatal week. In the subsequent postnatal development, Purkinje cells elaborate multiplanar dendrites in a 3D space (P18: three colors represent different dendritic branches arising from the soma), then eventually confine the trees into a 2D space (blue) by trimming branches (P22: Branches with yellow and magenta colors have been eliminated during this period). Both sagittal and coronal views are shown for P18 and P22 images. (D) Mammalian skin is composed of multiple layers of epidermal cells. Epidermal cells 
FIGURE 1 | Continued

are continuously generated from stem cells and move toward the upper layer of the skin (arrow). According to this epidermal cell turnover, the tight junctions (green dots) are also remodeled in the deep epidermal layer. DRG neurons typically maintain their sensory terminals (blue) underneath the tight junctions by extension, retraction, and pruning of the nerve ends. (E) Drosophila C4da neurons replace their larval dendrites with adult-specific arbors during metamorphosis. After establishing their dendritic fields in the pupal development, C4da neurons immediately reshape the dendritic arbors from the radial to the lattice-like structures in the first 1-2 adult days. APF; after pupal formation. (F) C. elegans IL2 sensory neurons typically elaborate simple unbranched dendrites in the normal condition. In response to adverse environmental conditions, however, IL2 neurons undergo dendrite remodeling, shifting from a bipolar to a multipolar state. This process is reversible: the arborized dendrites are pruned away after worms are returned to the normal (non-stressful) environment (bidirectional arrows). Anterior is shown at the top.

\section{DEVELOPMENTAL DENDRITE REMODELING IN INVERTEBRATE NEURONS}

Drosophila dendrite arborization (da) sensory neurons provide an excellent model to study the molecular and cellular basis for dendrite remodeling as class IV da (C4da) neurons undergo extensive dendrite remodeling during metamorphosis using multiple distinct cellular strategies (Williams and Truman, 2005; Emoto, 2012; Yu and Schuldiner, 2014; Kanamori et al., 2015b). Similar to Purkinje cells in the mammalian cerebellum, C4da neurons establish space-filling type dendrites during the larval stage within a $2 \mathrm{D}$ space between the epidermis and the musculature (Figure 1E). During metamorphosis in which flies transit from their larval to adult form within 5 days, larval C4da dendrites are completely removed from the soma by $\sim 24 \mathrm{~h}$ after pupal formation (Kuo et al., 2005; Williams and Truman, 2005). After completion of dendrite pruning, C4da neurons immediately initiate dendrite regeneration and re-establish adult-specific dendritic arbors on the epidermis by eclosion (Shimono et al., 2009; Yasunaga et al., 2010, 2015; Lyons et al., 2014; Kitatani et al., 2020). Interestingly, the dendritic arbors of adult C4da neurons are rapidly reshaped from a radial shape to a lattice-like shape within $24 \mathrm{~h}$ after eclosion (Yasunaga et al., 2010, 2015). This radial-to-lattice reshaping arises from rearrangement of the existing radial branches into the lattice-like pattern, rather than extensive dendrite pruning followed by regrowth of the lattice-shaped arbors over the period (Yasunaga et al., 2010).

Another good model for dendrite remodeling in invertebrates is motoneurons of the hawkmoth moth Manduca sexta (Consoulas et al., 2000). During metamorphosis, muscles of the larval abdominal body wall are replaced with newly generated adult muscles, whereas certain larval motoneurons survive metamorphosis to serve as adult motoneurons in Manduca (Truman and Reiss, 1976). To reestablish functional connectivity with adult muscles, motoneurons need to remodel their dendritic fields. Similar to Drosophila C4da neurons, Manduca motoneurons initially undergo dendrite regression followed by a massive extension of adult-specific trees during pupal development (Levine and Truman, 1985; Kent and Levine, 1993).

C. elegans sensory neurons are an emerging model system for studying the molecular basis for developmental dendrite remodeling. IL2 sensory neurons typically elaborate simple unbranched dendrites (Figure 1F). In response to adverse environmental conditions, however, IL2 neurons undergo dendrite remodeling, shifting from a bipolar to multipolar state (Schroeder et al., 2013). Intriguingly, this process is reversible: the arborized dendrites are pruned away after worms are returned to the normal (non-stressful) environment. Even in normal development, PVD sensory neurons exhibit dynamic dendrite remodeling by auto fusion between terminal branches to establish their characteristic dendritic trees (Oren-Suissa et al., 2010). Another interesting example of developmental dendrite remodeling is seen in the GABAergic DVB neurons, which display male-specific posteriorly oriented outgrowth, which changes significantly during development and shows dramatic changes that are experience- and activity-dependent (Hart and Hobert, 2018).

\section{DENDRITE REMODELING IN PATHOLOGY, INJURY, AND AGING}

Many types of neurons progressively reduce dynamics and stabilize their dendritic arbors as they mature (Emoto et al., 2006; Parrish et al., 2007b; Koleske, 2013). However, dendritic arbors of mature neurons can undergo dramatic regeneration under pathological conditions such as epilepsy and traumatic disorder (Murphy and Corbett, 2009). For instance, brain ischemia in mice induces dendrite remodeling in CA1 pyramidal neurons (Ruan et al., 2006). Similarly, post-traumatic stress disorder (PTSD)-like symptoms in mice is associated with the brain region-specific dendrite remodeling: the total number of dendrites is decreased in the prelimbic and increased in the infralimbic cortex (Lguensat et al., 2019).

Laser ablation of a part of dendrites in Drosophila C4da neurons induces robust dendrite regeneration (Song et al., 2012). Interestingly, injury-induced dendrite regeneration seems to be mechanistically distinct from developmental dendrite regeneration (Tao and Rolls, 2011) as well as initial dendrite development (Thompson-Peer et al., 2016). For example, dendritic branches from the same C4da neurons typically avoid overlapping in developmental regeneration as well as initial development, whereas dendrites fail to avoid overlapping with other branches from the same neurons in the injuryinduced regeneration (Emoto et al., 2004; Yasunaga et al., 2015; Thompson-Peer et al., 2016). Similar to Drosophila C4da neurons, laser ablation of dendrites in C. elegans PVD neurons at the L4 stage evokes branch regeneration responses (Oren-Suissa et al., 2017). Unlike dendrite regeneration in other organisms, severed primary dendrites grow toward each other and eventually reconnect via branch fusion.

Dendritic branches often degenerate as animals age, and this dendrite degeneration seems to be accelerated in aging-related neurodegenerative diseases (Lin and Koleske, 2010; Adalbert and Coleman, 2013). Aging-associated dendrite degeneration is 
also observed in Drosophila C4da neurons and C. elegans PVD neurons (Shimono et al., 2009; Lezi et al., 2018). In the course of aging-associated dendrite degeneration in PVD neurons, from day 1 to day 9 of adulthood, varicosity-like structures are progressively formed along the dendritic branches (Lezi et al., 2018). Further, fragmented microtubules are often observed in aged PVD dendrites, but not young dendrites. These progressive changes in dendrite morphology are similar to characteristics of the degenerating dendrites observed in mammalian and Drosophila neurons (Emoto et al., 2006; Kanamori et al., 2013, 2015a; Koleske, 2013), implying that the underlying molecular mechanisms might be similar.

\section{TEMPORAL CONTROL OF DENDRITE REMODELING}

\section{Neural Activity in Developmental Dendrite Remodeling}

In the developing mammalian nervous system, the neural activity often drives fine-tuning of the functional neural circuits through multiple cellular mechanisms including dendrite remodeling (Wong and Ghosh, 2002). Indeed, glutamate receptor (NMDA and AMPA receptors)-mediated synaptic transmission is required for dendrite remodeling in the layer IV neurons in the rodent barrel cortex (Figure 1C; Mizuno et al., 2014; Nakazawa et al., 2018). Similarly, pharmacological manipulation of afferent activity in the postnatal mice dampens the multiplanar-to-monoplanar transition of dendritic trees in Purkinje cells (Kaneko et al., 2011; Figure 1B).

In many sensory systems, the spontaneous activity generated by the sensory organ often fine-tunes connections to produce a precise nearest-neighbor relationship from sensory to higherorder neurons. For instance, in vivo imaging of the neonatal mouse brain reveals a propagating wave of activity from the retina through the entire visual system in the brain (Feller et al., 1996; Ackman et al., 2012; Ackman and Crair, 2014). Similarly, the spontaneous activity generated in the developing cochlea propagates to auditory brain regions (Tritsch et al., 2007). In both cases, pharmacological or genetic inhibition of the spontaneous activity disturbs functional refinement of the sensory circuits (Triplett et al., 2009). Dendrite remodeling in mitral cells is largely unaffected in mice lacking function of the olfactory cyclic nucleotide-gated $(\mathrm{CNG})$ channels that are required to evoke odor-triggered signaling in mitral cells (Lin et al., 2000) although a small delay in the remodeling was observed. Furthermore, in vivo imaging of dendrite remodeling in mitral cells indicates that over $50 \%$ of mitral cells complete dendrite remodeling before the animals' birth (Togashi et al., 2020), supporting the idea that odor-evoked activity in mitral cells is dispensable for dendrite remodeling. Indeed, a recent study suggested that spontaneous activity, rather than evoked activity, in the olfactory circuits might play a role in dendrite remodeling in mitral cells (Fujimoto et al., 2019).

In contrast to the vertebrate nervous system, there is little evidence supporting the role of neural activity in developmental dendrite degeneration and regeneration in invertebrates. However, several reports suggest activitydependent mechanisms in certain types of dendrite remodeling. For example, injury-induced dendrite regeneration requires neural activity in larval C4da neurons, although the neural activity is dispensable for initial dendrite growth during embryonic/larval stages as well as developmental dendrite remodeling during metamorphosis (Thompson-Peer et al., 2016). Unlike C4da neurons, neural activity promotes dendrite growth in developing Drosophila motoneurons (Vonhoff et al., 2013), but it remains to be determined whether activity might act in dendrite remodeling. Studies on Manduca motoneurons suggest a potential role of neural activity in dendrite remodeling during metamorphosis (Duch and Levine, 2002; Duch and Mentel, 2004).

\section{Transcriptional Control of Developmental Dendrite Remodeling}

Multiple aspects of dendrite development including remodeling processes are often under transcriptional control. Dendrite remodeling in Purkinje cells is regulated by the thyroid hormone and its receptor Retinoic acid-related orphan receptor alpha $(\mathrm{ROR} \alpha)$. ROR $\alpha$ was originally identified as the gene responsible for the ataxic mutant mouse staggerer (Sidman et al., 1962; Gold et al., 2007). Purkinje cells in staggerer mutant mice exhibit atrophic, fusiform-like dendrites lacking spiny branchlets (Landis and Sidman, 1978; Soha and Herrup, 1995). Further, overexpression of ROR $\alpha$ in wild-type Purkinje cells accelerates dendrite regression in organotypic cultures (Boukhtouche et al., 2006). These data suggest that ROR $\alpha$ mediates the regression of dendrites in the early phase of development. Besides, recent studies suggest that ROR $\alpha$ is required not only for the branch regression early in dendrite development but also for dendrite growth in later developmental stages through regulating expression levels of multiple different genes (Takeo et al., 2015; Hatsukano et al., 2017).

The BTB/POZ-type transcription factor BTBD3 is required for dendrite remodeling of the layer IV pyramidal neurons in the rodent barrel cortex (Matsui et al., 2013). Since BTBD3 is translocated from the cytosol to the nucleus in response to neural activity in pyramidal neurons, BTBD3 might function downstream of neural activity in dendrite remodeling. Similar dendrite remodeling defects in layer IV pyramidal neurons are observed in neurons defective for the transcription factor Lhx2 (Wang et al., 2017). Lhx2 is required for BTBD3 expression in somatosensory neurons in response to neural activity (Wang et al., 2017). Since Lhx2 is constitutively expressed in developing somatosensory neurons, Lhx2 likely functions as a permissive factor for BTBD3 expression in response to neural activity.

Dendrite remodeling in invertebrates is likewise subject to transcriptional control, with signaling by the steroid hormone ecdysone playing a key role in timing and execution of Drosophila C4da sensory neuron remodeling (Kuo et al., 2005; Williams and Truman, 2005). The molting hormone ecdysone is secreted from the prothoracic gland at precisely timed developmental intervals, with each peak of ecdysone triggering a major developmental transition (Yamanaka et al., 2013). One of the 
largest ecdysone pulses occurs at the end of larval development and triggers the initiation of metamorphosis, during which larval structures including sensory dendrites are extensively remodeled to the form they will take in the adult (Thummel, 2001). The ecdysone hormone binds to the nuclear receptor composed of a non-covalent heterodimer of two proteins, EcR and USP, which, in turn, induces multiple target genes. Among the downstream targets, the transcription factor SOX14 mediates dendrite pruning in C4da neurons as Sox 14 expression is induced during the early metamorphosis in an EcR/USP-dependent manner, and Sox14 mutant C4da neurons show defects in dendrite pruning presumably in part through inducing the E3 ligase Cullin1 (Wong et al., 2013). Although in vivo targets of Cullin1 in dendrite pruning remain unclear, one potential outcome might be the reduction of Akt levels in C4da neurons, leading to suppression of dendrite growth.

The transcription factor AP-1 (Jun) has been implicated in activity-dependent dendrite growth in Drosophila motoneurons (Hartwig et al., 2008; Vonhoff et al., 2013). Recent reports suggest that AP-1 likely acts downstream of JNK signaling in both developmental and injury-induced dendrite degeneration (Hao et al., 2019; Zhu et al., 2019), yet its transcriptional targets in dendrite remodeling remain elusive.

\section{MicroRNAs Trigger Developmental and Injury-Induced Dendrite Regeneration}

MicroRNAs (miRNAs) have recently emerged as key factors regulating developmental timing in the nervous system (Sun et al., 2013; Shenoy and Blelloch, 2014). Although miRNAs appear to play both positive and negative roles in axon regeneration after injury (Mahar and Cavalli, 2018), roles for miRNAs in dendrite regeneration have been elusive. A recent genetic screen in Drosophila C4da neurons has identified the miRNA $m i R-87$ as a critical regulator of dendrite regeneration (Kitatani et al., 2020). miR-87 knockout impairs dendrite regeneration after developmentally-programmed pruning, whereas $m i R-87$ overexpression in C4da neurons causes precocious initiation of dendrite regeneration. Genetic analyses indicate that the transcriptional repressor Tramtrack69 (Ttk69) is a functional target for miR-87-mediated repression as $t$ tk69 expression is increased in miR-87 knockout neurons and reducing ttk69 expression restores dendrite regeneration in $m i R-87$ neurons. Given that Ttk69 prevents progenitor cell differentiation by suppressing the expression of genes required for neural fate specification (Xiong and Montell, 1993; Li et al., 1997; Kniss et al., 2013), miR-87 might suppress Ttk69 function to reactivate the "neural differentiation" program including dendrite regrowth in C4da neurons. Interestingly, $m i R-87$ is required for dendrite regeneration after acute injury in the larval stage, as well as developmental dendrite regeneration (Kitatani et al., 2020). Since the miR-87 expression is upregulated in C4da neurons upon dendrite injury and functions by suppressing ttk69 expression, the miR-87-mediated ttk69 suppression is a common intrinsic mechanism to drive developmental and injury-induced dendrite regeneration.

\section{Intrinsic Signaling in Dendrite Degeneration and Regeneration After Injury}

In the axonal degeneration after injury, namely Wallerian degeneration, numerous signaling molecules are identified including NMNATs, SARM, MAPKs, and JNKs, and their roles in the axon degeneration seem to be conserved between invertebrates and vertebrates (Gilley and Coleman, 2014; Mahar and Cavalli, 2018). By contrast, much less is known about signaling pathways in dendrite regeneration after injury. Recent studies reported that JNK signaling is involved in both developmental and injury-induced dendrite degeneration in Drosophila C4da neurons (Hao et al., 2019; Zhu et al., 2019). In both cases, JNK acts through the canonical downstream effectors AP-1 (Jun) and Fos, but JNK signaling might play different roles in developmental and injury-induced dendrite degeneration (Hao et al., 2019; Zhu et al., 2019).

mTOR signaling promotes dendrite regeneration as well as axon regeneration after injury in vertebrates and invertebrates (Park et al., 2008; Duan et al., 2015; Agostinone et al., 2018; Beckers et al., 2019). Interestingly, mTOR is locally upregulated through local translocation of mRNAs at the injury sites in the axon regeneration (Terenzio et al., 2018), but how an injury could trigger the local translation remains elusive. Given that mTOR is required for both axon and dendrite regeneration, similar local translation for mTOR might work in dendrite regeneration as well.

The regenerative capacity of dendrites declines with age at least in invertebrates, which is the case in Drosophila C4da neurons (DeVault et al., 2018) and C. elegans PVD neurons (Kravtsov et al., 2017). In PVD neurons, the age-dependent dendrite regeneration is inhibited in part by the Insulin/IGF1 signaling pathway (Kravtsov et al., 2017).

\section{SPATIAL CONTROL OF DENDRITE REMODELING}

\section{Extrinsic Regulation}

\section{Cellular Interactions}

Since most axon pruning involves the removal of axons that had already made synaptic connections, axon pruning is tightly associated with synapse elimination. Indeed, repulsive signaling molecules such as Semaphorins and Ephrins are required for a large-scale axon degeneration in developing mammalian nervous systems (Riccomagno and Kolodkin, 2015). By contrast, no obvious requirement for repulsive molecules has been reported in developmental dendrite pruning. A recent study reported that a weak but significant delay in dendrite pruning in mitral cells is observed in mice lacking Sema7A and its potential receptor PlexinC1 (Inoue et al., 2018). Given that Sema7A is upregulated by the odor-evoked activity in olfactory sensory neurons and that Sema7A and PlexinC1 are both required for synapse formation (Inoue et al., 2018), Sema7A and PlexinC1 might contribute to synapse formation and/or stabilization of between sensory neuron axons and mitral cells dendrites. It remains to be elucidated whether Sema7A and 
PlexinC1 could contribute to the removal of the synapse connections through repulsive signaling. Indeed, the Semaphorin signaling functions in both synapse formation and disruption in the Drosophila giant fiber system (Godenschwege et al., 2002) and in synapse removal in murine hippocampal neurons (Liu et al., 2005).

In the case of the nerve end pruning in rodent nociceptive sensory neurons (Takahashi et al., 2019), in vivo imaging reveals that the nerve-epithelial interactions likely play a role in the spatial control of pruning, as the nerve ends tend to be pruned underneath the tight junctions within the epithelial cells (Takahashi et al., 2019). It is thus likely that tight junctions might provide unknown spatial cues to the nerve ends.

\section{Environmental Cues}

The interactions between dendrites and the extracellular matrix (ECM) have been implicated in regulating the structural plasticity of dendrites in vivo (Fujioka et al., 2012). For instance, blockage of the integrin-ECM interaction in retina ganglion cells or genetic ablation of the integrin-mediated signaling in adult cortical neurons causes progressive retraction of dendritic branches (Moresco et al., 2005; Marrs et al., 2006). ECM modifications in the nervous system are typically achieved by the concerted actions of several different proteases that are secreted by neurons and glial cells in vertebrates and invertebrates (Yong, 2005; Page-McCaw et al., 2007). In particular, matrix metalloproteases (MMPs) are the likely regulators in dendrite development and pathology (SekineAizawa et al., 2001; Szklarczyk et al., 2002). Indeed, the dendrite reshaping of Drosophila C4da neurons after eclosion is triggered through ECM modification by the epithelial-derived MMP2 (Yasunaga et al., 2010). In addition to the dendrite reshaping, Drosophila MMP2-mediated ECM modification is associated with the reduced capacity of dendrite regeneration with aging as inhibiting MMP-2 preserves the ability of dendrite regeneration in $\mathrm{C} 4 \mathrm{da}$ neurons as the animal aged (DeVault et al., 2018). In the mouse cerebellum, the membrane-type 5 MMP (MT5-MMP; also named MMP-24) is highly expressed in developing dendrites of Purkinje cells (Sekine-Aizawa et al., 2001), implying a potential role of MT5-MMP in PC dendrite remodeling. Importantly, MMP expression levels are elevated after nervous system injury and in several neuronal pathologies. Furthermore, after a seizure, MMP-9 mRNA is transported to dendrites and synapses in the hippocampal DG of kainic acid-treated rats (Konopacki et al., 2007). Thus, MMP-mediated EMC modification might contribute to injury and pathologyinduced dendrite remodeling as well as developmental dendrite remodeling. MMP activity is required for axon degeneration and regeneration (Andries et al., 2017).

In C. elegans PVD neurons, an antimicrobial peptide, namely NLP-29, secreted from the epidermis drives aging-associated dendrite degeneration (Lezi et al., 2018). NLP-29 expression is increased along with aging under the control of the innate immune signaling pathway, and the secreted NPL-29 is received by the G protein-coupled receptor NPR-12 in PVD neurons (Lezi et al., 2018). As expected from its regulation by the innate immune signaling, NLP-29 is also required for the fungal infection-associated dendrite degeneration in PVD neurons (Lezi et al., 2018).

\section{Intrinsic Regulators}

\section{Caspase Activity and Intracellular Calcium Levels}

Developmental dendrite degeneration is often achieved in a compartmentalized manner (Kanamori et al., 2015b; Riccomagno and Kolodkin, 2015). How neurons can compartmentalize the degeneration activities into particular branches is an important issue to be addressed. Caspases are required for dendrite pruning as well as axon degradation, and the caspase activity is typically restricted in dendritic branches during dendrite pruning in Drosophila C4da neurons (Kuo et al., 2006; Williams et al., 2006) and in axonal branches in Wallerian degeneration (Cusack et al., 2013; Unsain et al., 2013). In the case of axon degeneration, caspase activity is spatially determined by the expression of the Inhibitor of apoptosis protein (IAP) in the soma and dendritic branches, which suppresses caspase activity in the soma and dendritic branches, therefore confining caspase activity in the axonal compartment (Potts et al., 2003; Cusack et al., 2013; Unsain et al., 2013). Also, proteasome activity spatially controls caspases as well as IAP through local degradation in Wallerian degeneration (Potts et al., 2003; Cusack et al., 2013; Unsain et al., 2013). Though not yet determined, dendrite pruning might also utilize similar strategies to restrict caspase activity.

Another factor that functions in dendrite pruning in a compartmentalized manner is intracellular calcium $\left(\mathrm{Ca}^{2+}\right)$. Time-lapse imaging of pruning dendrites in Drosophila C4da neurons reveals low frequency $(\sim 0.01 \mathrm{~Hz}) \mathrm{Ca}^{2+}$ transients in dendritic branches that are destined to be pruned (Kanamori et al., 2013). Interestingly, these compartmentalized $\mathrm{Ca}^{2+}$ transients are observed $\sim 3 \mathrm{~h}$ before dendrite severing, and completely predict the location and timing of the dendrite pruning. The voltage-gated $\mathrm{Ca}^{2+}$ channels (VGCCs) are responsible for generating $\mathrm{Ca}^{2+}$ transients, and mutant C4da neurons lacking the VGCC activity show significant defects in dendrite pruning, suggesting that the dendritic $\mathrm{Ca}^{2+}$ transients are predominantly composed of $\mathrm{Ca}^{2+}$ influx through VGCCs. Given that VGCCs are activated by depolarization of membrane potential, membrane potential might be locally changed in dendritic compartments, which in turn drives $\mathrm{Ca}^{2+}$ transients. Subsequent calcium signaling activates the $\mathrm{Ca}^{2+}$-dependent protease calpains that promote dendrite degeneration cooperatively with the activity of caspases (Kuo et al., 2006; Williams et al., 2006; Kanamori et al., 2013). Unlike caspase activity, $\mathrm{Ca}^{2+}$ transients are restricted in particular dendritic compartments in part by physical barriers that are formed in the proximal dendrites (Kanamori et al., 2015a). Interestingly, calpains and caspases function cooperatively in both developmental and injury-induced axon degeneration in the mouse visual system (Yang et al., 2013). It is thus likely that the $\mathrm{Ca}^{2+}$ transient-activated protease system functions in axon degeneration as well as dendrite degeneration in invertebrates and vertebrates. Additionally, a recent article reports that the low-frequency $\mathrm{Ca}^{2+}$ transients drive not only dendrite pruning but also 
synapse pruning in the neuromuscular junctions in Drosophila (Vonhoff and Keshishian, 2017).

\section{Rearrangement of Cytoskeletal Structures}

Microtubule (MT) organization is important for both the degeneration and regeneration of dendritic trees (Rolls et al., 2020). In developmental dendrite degeneration in Drosophila C4da neurons, MT breakdown is the earliest detectable event in dendrite pruning (Williams and Truman, 2005; Kanamori et al., 2015a; Herzmann et al., 2018). MT breakdown and subsequent disassembly in developmental dendrite degeneration are mediated by multiple factors including Kat-L60, Fidgetin, and Par-1 (Lee et al., 2009; Tao et al., 2016; Herzmann et al., 2017). Also, MT polarity organization in dendrites is a critical factor for efficient degeneration of dendrites. Unlike mammalian dendrites, dendritic MTs exhibit the minus-end-out polarity in Drosophila C4da dendrites (Stone et al., 2008). Knockdown of the genes involved in the control of the dendrite MT polarity such as patronin and kinesins causes significant defects in dendrite pruning in Drosophila C4da neurons (Herzmann et al., 2018; Wang et al., 2019).

A recent study in Drosophila C4da neurons has identified the receptor tyrosine kinase-like orphan receptor (Ror) as a critical factor for dendrite regeneration after injury (Nye et al., 2020). Subsequent studies suggest that Ror promotes TM nucleation for dendritic branch growth in cooperation with the Wnt signaling pathway (Nye et al., 2020; Weiner et al., 2020).

\section{Membrane Dynamics}

Recent studies in invertebrate models indicate that local membrane dynamics in dendritic branches impact dendrite remodeling. In the course of dendrite pruning in Drosophila C4da neurons, the first morphological alterations are observable in the proximal regions of dendrites: proximal dendrites actively form varicosities and dendritic branches progressively become thinner, which eventually compartmentalizes distal parts of the dendrites (Williams and Truman, 2005; Kirilly et al., 2009; Kanamori et al., 2015a). This compartmentalization of dendritic branches is driven by local endocytosis at proximal dendrites (Kanamori et al., 2015a). Genetic inhibition of Rab5and Shibire/Dynamin-dependent endocytosis suppresses the dendrite thinning at proximal dendrites and also impairs initiation of $\mathrm{Ca}^{2+}$ transients in distal dendrites, suggesting that the local membrane dynamics at proximal dendrites spatially defines dendrite pruning. In addition to the local endocytosis at proximal dendrites, global endocytosis contributes to dendrite pruning in C4da neurons in part through endosomal degradation of the L1-type cell-adhesion molecule Neuroglian (Nrg; Zhang et al., 2014; Zong et al., 2018; Krämer et al., 2019). The $\mathrm{Nrg}$ degradation starts from the onset of metamorphosis, and loss-of-function $\mathrm{nrg}$ mutant neurons show precocious dendrite pruning. Thus, the removal of $\mathrm{Nrg}$ from the cell surface acts as a prerequisite for dendrite pruning. Indeed, genetic evidence suggests that this global endocytosis for $\mathrm{Nrg}$ degradation functions in dendrite pruning cooperatively with the local endocytosis for the compartmentalized $\mathrm{Ca}^{2+}$ transients (Kanamori et al., 2015a).
The type I membrane protein EFF-1, which was originally identified as a cell fusion-promoting factor, regulates the complexity of dendritic arbors by pruning excessive dendritic branches in C. elegans PVD neurons (Oren-Suissa et al., 2010). Consistently, the pruning process involves not only dendrite severing and retraction but also dendrite-dendrite auto fusion. Furthermore, EFF-1 mediates dendrite repair after injury by promoting membrane fusion between elongating dendritic branches (Oren-Suissa et al., 2017). Interestingly, AFF-1 fusogen, a paralog of EFF-1 expressed in neighboring hypodermal cells but not the neuron, also contributes to dendrite repair, possibly through extracellular vesicle-cell fusion (Oren-Suissa et al., 2017). A recent report proposed that EFF-1 regulates PVD dendrite morphology in part by patterning the cell adhesion molecule SAX-7 distribution in hypodermal cells (Zhu et al., 2017). It remains to be elucidated whether similar fusogen proteins might play a role in developmental and injury-induced dendrite remodeling in other organisms.

\section{FUTURE PERSPECTIVES}

In the past decade, considerable progress has been made in understanding the molecular mechanisms underlying dendrite remodeling including branch regeneration and degeneration in vivo, but many questions remain as to how the sequential rounds of branch degeneration and regeneration in developing dendrites are regulated by coordinated actions of the identified molecules. In particular, spatial regulation of dendrite degeneration and regeneration is still largely elusive. For instance, how the layer IV pyramidal neurons could selectively degenerate and regenerate apical and basal dendrites, respectively, is unknown (Figure 1D). It is even harder to imagine how Purkinje cells can confine 3D dendritic arbors into 2D arbors (Figure 1C). To tackle these interesting but difficult questions, developing novel optogenetic tools for local manipulation of molecular activity in dendrites should be a powerful approach. It should be also useful to develop in vivo imaging systems to precisely monitor multiple molecular activities in dendrites. Also, studies using Drosophila models have provided several molecular clues that could bridge our knowledge gaps in the spatiotemporal regulation of dendrite remodeling. First, given that microRNAs are the potential factors that drive the temporal transition from dendrite degeneration to regeneration, further identification of the downstream targets should be an efficient way for further understanding of the temporal control. Second, $\mathrm{Ca}^{2+}$ transients and Caspase activity can be good readouts to identify molecules involved in the spatial control of dendrite compartmentalization. The field is only at the starting point in terms of understanding how the components function together in dendrite degeneration and regeneration.

\section{AUTHOR CONTRIBUTIONS}

All authors made intellectual contributions to the manuscript and wrote the article. All authors contributed to the article and approved the submitted version. 


\section{FUNDING}

This work was supported by MEXT Grants-in-Aid for promoting young researchers to KF: MEXT Grants-in-Aid for Scientific Research on Innovative Areas "Dynamic regulation of brain function by Scrap and Build system" (KAKENHI 16H06456), JSPS (KAKENHI 16H02504), WPI-IRCN, AMED-CREST (JP18gm0610014), JST-CREST, the Strategic Research Program

\section{REFERENCES}

Ackman, J. B., and Crair, M. C. (2014). Role of emergent neural activity in visual map development. Curr. Opin. Neurobiol. 24, 166-175. doi: 10.1016/j.conb. 2013.11.011

Ackman, J. B., Burbridge, T. J., and Crair, M. C. (2012). Retinal waves coordinate patterned activity throughout the developing visual system. Nature 490, 219-225. doi: 10.1038/nature11529

Adalbert, R., and Coleman, M. P. (2013). Axon pathology in age-related neurodegenerative disorders. Neuropathol. Appl. Neurobiol. 39, 90-108. doi: 10. 1111/j.1365-2990.2012.01308.x

Agostinone, J., Alarcon-Martinloaez, L., Gamlin, C., Yu, W. Q., Wong, R. O. L., and Di Polo, A. (2018). Insulin signaling promotes dendrite and synapse regeneration and restores circuit function after axonal injury. Brain 141, 1963-1980. doi: 10.1093/brain/awy142

Andries, L., Van Hove, I., Moons, L., and De Groef, L. (2017). Matrix metalloproteinases during axonal regeneration, a multifactorial role from start to finish. Mol. Neurobiol. 54, 2114-2125. doi: 10.1007/s12035-016-9801-x

Batista, G., and Hensch, T. K. (2019). Critical period regulation by thyroid hormone: potential mechanisms and sex-specific aspects. Front. Mol. Neurosci. 12:77. doi: 10.3389/fnmol.2019.00077

Beckers, A., Van Dyck, A., Bollaerts, I., Van Houcke, J., Lefevere, E., Andries, L., et al. (2019). An antagonistic axon-dendrite interplay enables efficient neuronal repair in the adult zebrafish central nervous system. Mol. Neurobiol. 56, 3175-3192. doi: 10.1007/s12035-018-1292-5

Boukhtouche, F., Janmaat, S., Vodjdani, G., Gautheron, V., Mallet, J., Dusart, I., et al. (2006). Retinoid-related orphan receptor alpha controls the early steps of Purkinje cell dendritic differentiation. J. Neurosci. 26, 1531-1538. doi: 10.1523/JNEUROSCI.4636-05.2006

Consoulas, C., Duch, C., Bayline, R. J., and Levine, R. B. (2000). Behavioral transformations during metamorphosis: remodeling of neural and motor systems. Brain Res. Bull. 53, 571-583. doi: 10.1016/s0361-9230(00) 00391-9

Cusack, C. L., Swahari, V., Henley, W. H., Ramsey, J. M., and Deshmukh, M. (2013). Distinct pathways mediate axon degeneration during apoptosis and axon-specific pruning. Nat. Commun. 4:1876. doi: 10.1038/ ncomms 2910

DeVault, L., Li, T., Izabel, S., Thompson-Peer, K. L., Jan, L. Y., and Jan, Y. N. (2018). Dendrite regenerstion of adult Drosophila sensory neurons diminishes with aging and is inhibited by epidermal-derived matrix metalloproteinase 2 . Genes Dev. 32, 402-414. doi: 10.1101/gad.308270.117

Duan, X., Qiao, M., Bei, F., Kim, I. J., He, Z., and Sanes, J. R. (2015). Subtypespecific regeneration of retinal ganglion cells following axotomy: effects of osteopontin and mTOR signaling. Neuron 85, 1244-1256. doi: 10.1016/j. neuron.2015.02.017

Duch, C., and Levine, R. B. (2002). Changes in calcium signaling during postembryonic dendritic growth in meduca sexta. J. Neurophysiol. 87, 1415-1425. doi: 10.1152/jn.00524.2001

Duch, C., and Mentel, T. (2004). Activity affects dendritic shape and synapse elimination during steroid controlled dendrite retraction in menduca sexta. J. Neurosci. 24, 9826-9837. doi: 10.1523/JNEUROSCI.3189-04.2004

Emoto, K. (2011). Dendrite remodeling in development and disease. Dev. Growth Differ. 53, 277-286. doi: 10.1111/j.1440-169X.2010.01242.x

Emoto, K. (2012). Signaling mechanisms that coordinate the development and maintenance of dendritic fields. Curr. Opin. Neurobiol. 22, 805-811. doi: 10.1016/j.conb.2012.04.005 for Brain Sciences, Toray Foundation, Naito Foundation, Takeda Science Foundation, and Uehara Memorial Foundation to KE.

\section{ACKNOWLEDGMENTS}

We apologize to all researchers whose works could not be cited due to space limitations.

Emoto, K., He, Y., Ye, B., Grueber, W. B., Adler, P. N., Jan, L. Y., et al. (2004). Control of dendritic branching and tiling by the tricorneredkinase/furry signaling pathway in Drosophila sensory neurons. Cell 119, 245-256. doi: 10.1016/j.cell.2004.09.036

Emoto, K., Parrish, J. Z., Jan, L. Y., and Jan, Y.-N. (2006). The tumour suppressor hippo acts with the NDR kinases in dendrite tiling and maintenance. Nature 443, 210-213. doi: 10.1038/nature05090

Espinosa, J. S., Wheeler, D. G., Tsien, R. W., and Luo, L. (2009). Uncoupling dendrite growth and patterning: single-cell knockout analysis of NMDA receptor 2B. Neuron 62, 205-217. doi: 10.1016/j.neuron.2009.03.006

Feller, M. B., Wellis, D. P., Stellwagen, D., Werblin, F. S., and Shatz, C. J. (1996). Requirement for cholinergic synaptic transmission in the propagation of spontaneous retinal waves. Science 272, 1182-1187. doi: 10.1126/science.272. 5265.1182

Fujioka, H., Dairyo, Y., Yasunaga, K., and Emoto, K. (2012). Neural functions of matrix metalloproteinases: plasticity, neurogenesis, and disease. Biochem. Res. Int. 2012:789083. doi: 10.1155/2012/789083. [Epub ahead of print].

Fujimoto, S., Leiwe, M. N., Sakaguchi, R., Muroyama, Y., Kobayakawa, R., Kobayakawa, K., et al. (2019). Spontaneous activity generated within the olfactory bulb establishes the discrete wiring of mitral cell dendrites. BioRxiv [Preprint]. Available online at: https://www.biorxiv.org/content/ 10.1101/625616v1.full.pdf.

Gilley, C. L., and Coleman, M. P. (2014). Wallerian degeneration: an emerging axon death pathway linking injury and disease. Nat. Rev. Neurosci. 15, 394-409. doi: $10.1038 / \mathrm{nrn} 3680$

Godenschwege, T. A., Hu, H., Shan-Crofts, X., Goodman, C. S., and Murphey, R. K. (2002). Bi-directional signaling by Semaphorin 1a during central synapse formation in Drosophila. Nat. Neurosci. 5, 1294-1301. doi: 10. 1038/nn976

Gold, D. A., Gent, P. M., and Hamilton, B. A. (2007). ROR alpha in genetic control of cerebellum development: 50 staggering years. Brain Res. 1140, 19-25. doi: 10.1016/j.brainres.2005.11.080

Hao, Y., Waller, T. J., Nye, D. M., Li, J., Zhang, Y., Hume, R. I., et al. (2019). Degeneration of injured axons and dendrites requires restraint of a protective JNK signaling pathway by the transmembrane protein Raw. J. Neurosci. 39, 8457-8470. doi: 10.1523/JNEUROSCI.0016-19.2019

Hart, M. P., and Hobert, O. (2018). Neurexin controls plasticity of a mature, sexually dimorphic neuron. Nature 553, 165-170. doi: 10.1038/nature 25192

Hartwig, C. L., Worrell, J., Levine, R. B., Ramaswami, M., and Sanyal, S. (2008). Normal dendrite growth in Drosophila motor neurons requires the AP-1 transcription factor. Dev. Neurobiol. 68, 1225-1242. doi: 10.1002/dneu. 20655

Hatsukano, T., Kurisu, J., Fukumitsu, K., Fujishima, K., and Kengaku, M. (2017). Thyroid hormone induces PGC-1 $\alpha$ during dendritic outgrowth in mouse cerebellar Purkinje cells. Front. Cell. Neurosci. 11:133. doi: 10.3389/fncel.2017. 00133

Herzmann, S., Gotzelmann, I., Reekers, L.-F., and Rumpf, S. (2018). Spatial regulation of microtubule disruption during dendrite pruning in Drosophila. Development 145:dev156950. doi: 10.1242/dev.156950

Herzmann, S., Krumkamp, R., Rode, S., Kintrup, C., and Rumpf, S. (2017). PAR1 promotes microtubule breakdown during dendrite pruning in Drosophila. EMBO J. 36, 1981-1991. doi: 10.15252/embj.201695890

Inoue, N., Nishizumi, H., Naritsuka, H., Kiyonari, H., and Sakano, H. (2018). Sema7A/PlxnCl signaling triggers activity-dependent olfactory synapse formation. Nat. Commun. 9:1842. doi: 10.1038/s41467-018-04239-z 
Jan, Y.-N., and Jan, L. Y. (2010). Branching out: mechanisms of dendritic arborization. Nat. Rev. Neurosci. 11, 316-328. doi: 10.1038/nrn2836

Kanamori, T., Kanai, M., Dairyo, Y., Yasunaga, K., Morikawa, R., and Emoto, K. (2013). Compartmentalized calcium transients trigger dendrite pruning in Drosophila sensory neurons. Science 340, 1475-1478. doi: 10.1126/science. 1234879

Kanamori, T., Togashi, K., Koizumi, H., and Emoto, K. (2015b). Dendrite remodeling: lessons from invertebrate models systems. Int. Rev. Cell Mol. Biol. 318, 1-25. doi: 10.1016/bs.ircmb.2015.05.001

Kanamori, T., Yoshino, J., Yasunaga, K., Dairyo, Y., and Emoto, K. (2015a). Local endocytosis triggers dendrite thinning and pruning in Drosophila sensory neurons. Nat. Commun. 6:6515. doi: 10.1038/ncomms7515

Kaneko, M., Yamaguchi, K., Eiraku, M., Sato, M., Takata, N., Kiyohara, Y., et al. (2011). Remodeling of monoplanar Purkinje cell dendrites during cerebellar circuit formation. PLoS One 6:e20108. doi: 10.1371/journal.pone. 0020108

Kent, K. S., and Levine, R. B. (1993). Dendritic reorganization of an identified neuron during metamorphosis of the moth Menduca sexta: the influence of interaction with the periphery. J. Neurobiol. 24, 1-22. doi: 10.1002/neu. 480240102

Kirilly, D., Gu, Y., Huang, Y., Wu, Z., Bashirullar, A., Low, B. C., et al. (2009). A genetic pathway composed of sox14 and mical governs severing of dendrites during pruning. Nat. Neurosci. 12, 1497-1505. doi: 10.1038/nn.2415

Kitatani, Y., Hasegawa, E., Tezuka, A., Yagagi, S., Togashi, K., Tsuji, M., et al. (2020). Drosophila miR-87 promotes dendrite regeneration by targeting the transcriptional repressor tramtrack69. PLoS Genet. 16:e1008942. doi: 10.1371/journal.pgen.1008942

Kniss, J. S., Holbrook, S., and Mergman, T. G. (2013). R7 photoreceptor axon growth is temporally controlled by the transcription factor Ttk69, which inhibits growth in part by promoting transforming growth factor$\beta$ /activin signaling. J. Neurosci. 33, 1509-1520. doi: 10.1523/JNEUROSCI. 2023-12.2013

Koleske, A. J. (2013). Molecular mechanisms of dendrite stability. Nat. Rev. Neurosci. 14, 536-550. doi: 10.1038/nrn3486

Konopacki, F. A., Rylski, M., Wilczek, E., Amborska, R., Detka, D., Kaczmarek, L., et al. (2007). Synaptic localization of seizure-induced matrix metalloproteinase9 mRNA. Neuroscience 150, 31-39. doi: 10.1016/j.neuroscience.2007.08.026

Krämer, R., Rode, S., and Rumpf, S. (2019). Rab11 is required for neurite pruning and developmental membrane protein degradation in Drosophila sensory neurons. Dev. Biol. 451, 68-78. doi: 10.1016/j.ydbio.2019.03.003

Kravtsov, V., Oren-Suissa, M., and Podbilewicz, B. (2017). The fusogen AFF-1 can rejuvenate the regenerative potential of adult dendritic trees by self-fusion. Development 144, 2364-2374. doi: 10.1242/dev.150037

Kuo, C. T., Jan, L. Y., and Jan, Y. N. (2005). Dendrite-specific remodeling of Drosophila sensory neurons requires matrix metalloproteases, ubiquitinproteasome and ecdysone signaling. Proc. Natl. Acad. Sci. U S A 120, 15230-15235. doi: 10.1073/pnas.0507393102

Kuo, C. T., Zhu, S., Younger, S., Jan, L. Y., and Jan, Y. N. (2006). Identification of E2/E3 ubiquitinating enzymes and caspase activity regulating Drosophila sensory neuron dendrite pruning. Neuron 51, 283-290. doi: 10.1016/j.neuron. 2006.07.014

Landis, D. M., and Sidman, R. L. (1978). Electron microscopic analysis of postnatal histogenesis in the cerebellar cortex of staggerer mutant mice. J. Comp. Neurol. 179, 831-863. doi: 10.1002/cne.901790408

Lee, H.-H., Jan, L. Y., and Jan, Y.-N. (2009). Drosophila IKK-related kinase Ik2 and Katanin p60-like 1 regulate dendrite pruning of sensory neuron during metamorphosis. Proc. Natl. Acad. Sci. U S A 106, 6363-6368. doi: 10.1073/pnas. 0902051106

Levine, R. B., and Truman, J. W. (1985). Dendritic reorganization of an identified motoneuron during metamorphosis of the tobacco hornworm moth. J. Neurosci. 5, 2424-2431. doi: 10.1523/JNEUROSCI.05-09-02424.1985

Lezi, L., Zhou, T., Koh, S., Chuang, M., Sharma, R., Pujol, N., et al. (2018). An antimicrobial peptide and its neuronal receptor regulate dendrite degeneration in aging and infection. Neuron 97, 125.e5-138.e5. doi: 10.1016/j.neuron.2017. 12.001

Lguensat, A., Bentefour, Y., Bennis, M., Ba-M'hamed, S., and Garcia, R. (2019). Susceptibility and resilience to PTSD-like symptoms in mice are associated with opposite dendritic changes in the prelimbic and infralimbic cortices following trauma. Neuroscience 418, 166-176. doi: 10.1016/j.neuroscience.2019. 08.018

Li, S., Li, Y., Carthew, R. W., and Lai, Z. C. (1997). Photoreceptor cell differentiation requires regulated proteolysis of the transcriptional repressor tramtrack. Cell 90, 469-478. doi: 10.1016/s0092-8674(00)80507-3

Lin, Y.-C., and Koleske, A. J. (2010). Mechanisms of synapse and dendrite maintenance and their disruption in psychiatric and neurodegenerative disorders. Annu. Rev. Neurosci. 33, 349-378. doi: 10.1146/annurev-neuro060909-153204

Lin, D. M., Wang, F., Lowe, G., Gold, G. H., Axel, R., Ngai, J., et al. (2000). Formation of precise connections in the olfactory bulb occurs in the absence of odorant-evoked neuronal activity. Neuron 26, 69-80. doi: 10.1016/s0896-6273 (00)81139-3

Liu, H.-H., and Jan, Y.-N. (2020). Mechanisms of neurite repair. Curr. Opin. Neurobiol. 63, 53-58. doi: 10.1016/j.conb.2020.02.010

Liu, X. B., Low, L. K., Jones, E. G., and Cheng, H. J. (2005). Stereotyped axon pruning via plexin signaling is associated with synaptic complex elimination in the hippocampus. J. Neurosci. 25, 9124-9134. doi: 10.1523/JNEUROSCI.264805.2005

Lyons, G. R., Anderson, R. O., Abdi, K., Song, W.-S., and Kuo, C. T. (2014). Cysteine proteinase- 1 and cut protein isoform control dendritic innervation of two distinct sensory fields by a single neuron. Cell Rep. 6, 783-791. doi: 10.1016/j.celrep.2014.02.003

Mahar, M., and Cavalli, V. (2018). Intrinsic mechanisms of neuronal axon regeneration. Nat. Rev. Neurosci. 19, 323-337. doi: 10.1038/s41583-0180001-8

Marrs, G. S., Honda, T., Fuller, L., Thangavel, R., Balsamo, J., Lilien, J., et al (2006). Dendritic arbors of developing retinal ganglion cells are stabilized by $\beta 1$-integrins. Mol. Cell Neurosci. 32, 230-241. doi: 10.1016/j.mcn.2006. 04.005

Matsui, A., Tran, M., Yoshida, A. C., Kikuchi, S. S., U, M., Ogawa, M., et al. (2013). BTBD3 controls dendrite orientation toward active axons in mammalian neocortex. Science 342, 1114-1118. doi: 10.1126/science.1244505

Mizuno, H., Luo, W., Tarusawa, E., Saito, Y. M., Sato, T., Yoshimura, Y., et al. (2014). NMDA regulated dynamics of layer 4 neuronal dendrites during thalamocortical reorganization in neonates. Neuron 82, 365-379. doi: 10.1016/j. neuron.2014.02.026

Molnar, Z., Luhmann, H., and Kanold, P. O. (2020). Transient conrtical circuits match spontaneous and sensory-driven activity during development. Science 370:eabb2153. doi: 10.1126/science.abb2153

Moresco, E. M. Y., Donaldson, S., Williamson, A., and Koleske, A. J. (2005). Integrin-mediated dendrite branch maintenance requires Abelson (Abl) family kinases,". J. Neurosci. 25, 6105-6118. doi: 10.1523/JNEUROSCI.143205.2005

Mori, K., and Sakano, H. (2011). How is the olfactory map formed and interpreted in the mammalian brain?. Annu. Rev. Neurosci. 34, 467-499. doi: 10.1146/annurev-neuro-112210-112917

Murphy, T. H., and Corbett, D. (2009). Plasticity during stroke recovery: from synapse to behavior. Nat. Rev. Neurosci. 10, 861-872. doi: 10.1038/nrn2735

Murthy, V. N. (2011). Olfactory maps in the Brain. Annu. Rev. Neurosci. 34, 233-258. doi: 10.1146/annurev-neuro-061010-113738

Nakazawa, S., Mizuno, H., and Iwasato, T. (2018). Different dynamics of cortical neuron dendrite trees revealed by long-term in vivo imaging in neonates. Nat. Commun. 9:3106. doi: 10.1038/s41467-018-05563-0

Nye, D. M. R., Albertson, R. M., Weiner, A. T., Hertzler, J. I., Shorey, M., Goberdhan, D. C. I., et al. (2020). The receptor tyrosine kinase Ror is required for dendrite regeneration in Drosophila neurons. PLoS Biol. 18:e300065. doi: 10.1371/journal.pbio.3000657

Oren-Suissa, M., Gattegno, T., Kravtsov, V., and Podbilewicz, B. (2017). Extrinsic repair of injured dendrites as a paradigm for regeneration by fusion in Caenorhabditis elegans. Genetics 206, 215-230. doi: 10.1534/genetics.116. 196386

Oren-Suissa, M., Hall, D. H., Treinin, M., Shemer, G., and Podbilewicz, B. (2010). The fusogen EFF-1 controls sculpting of mechanosensory dendrites. Science 328, 1285-1288. doi: 10.1126/science.1189095

Page-McCaw, A., Ewald, A. J., and Werb, Z. (2007). Matrix metalloproteinases and the regulation of tissue remodelling. Nat. Rev. Mol. Cell Biol. 8, 221-233. doi: $10.1038 / \mathrm{nrm} 2125$ 
Park, K. K., Liu, K., Hu, Y., Smith, P. D., Wang, C., Cai, B., et al. (2008). Promoting axon regeneration in the adult CNS by modulation of the PTEN/mTOR pathway. Science 322, 963-966. doi: 10.1126/science.1161566

Parrish, J. Z., Emoto, K., Jan, L. Y., and Jan, Y. N. (2007a). Polycomb genes interact with the tumor suppressor genes hippo and warts in the maintenance of Drosophila sensory neuron dendrites. Genes Dev. 21, 956-972. doi: 10.1101/gad.1514507

Parrish, J. Z., Emoto, K., Kim, M. D., and Jan, Y. N. (2007b). Mechanisms that regulate establishment, maintenance and remodeling of dendritic fields. Annu. Rev. Neurosci. 30, 399-423. doi: 10.1146/annurev.neuro.29.051605.112907

Potts, P. R., Singh, S., Knezek, M., Thompson, C. B., and Deshmukh, M. (2003). Critical function of endogenous XIAP in regulating caspase activation during sympathetic neuronal apoptosis. J. Cell Biol. 163, 789-799. doi: 10.1083/jcb. 200307130

Riccomagno, M. M., and Kolodkin, A. L. (2015). Sculpting neural circuits by axon and dendrite pruning. Annu. Rev. Cell Dev. Biol. 32, 779-805. doi: 10.1146/annurev-cellbio-100913-013038

Richardson, C. E., and Shen, K. (2019). Neurite development and repair in worm and flies. Annu. Rev. Neurosci. 42, 209-226. doi: 10.1146/annurev-neuro070918-050208

Rolls, M. M., Thyagarajan, P., and Feng, C. (2020). Microtubule dynamics in healthy and injured neurons. Dev. Neurobiol. doi: 10.1002/dneu.22746. [Epub ahead of print].

Ruan, Y.-W., Zou, B., Fan, Y., Li, Y., Lin, N., Zeng, Y.-S., et al. (2006). Dendritic plasticity of CA1 pyramidal neurons after transient global ischemia. Neuroscience 140, 191-201. doi: 10.1016/j.neuroscience.2006.01.039

Sakano, H. (2020). Developmental regulation of olfactory circuit formation in mice. Dev. Growth Differ. 62, 199-213. doi: 10.1111/dgd.12657

Schroeder, N. E., Androwski, R. J., Rashid, A., Lee, H., Lee, J., and Barr, M. M. (2013). Dauer-specific dendrite arborization in C. elegans is regulated by KPC1/Furin. Curr. Biol. 23, 1527-1535. doi: 10.1016/j.cub.2013.06.058

Sekine-Aizawa, Y., Hama, E., Watanabe, K., Tsubuki, S., Kanai-Azuma, M., Kanai, Y., et al. (2001). Matrix metalloproteinase (MMP) system in brain: identification and characterization of brain-specific MMP highly expressed in cerebellum. Eur. J. Neurosci. 13, 935-948. doi: 10.1046/j.0953-816x.2001. 01462.x

Shenoy, A., and Blelloch, R. H. (2014). Regulation of microRNA function in somatic stem cell proliferation and differentiation. Nat. Rev. Mol. Cell Biol. 15, 565-576. doi: 10.1038/nrm3854

Shimono, K., Fujimoto, A., Tsuyama, T., Yamamoto-Kochi, M., Sato, M., Hattori, Y., et al. (2009). Multidendritic sensory neurons in the adult Drosophila abdomen: origins, dendritic morphology and segment- and age-dependent programmed cell death. Neural Dev. 4:37. doi: 10.1186/17498104-4-37

Sidman, R. L., Lane, P. W., and Dickie, M. M. (1962). Staggerer a new mutation in the mouse affecting the cerebellum. Science 137, 610-612. doi: 10.1126/science. 137.3530 .610

Soha, J. M., and Herrup, K. (1995). Stunted morphologies of cerebellar Purkinje cells in lurcher and staggerer mice are cell-intrinsic effects of the mutant genes. J. Comp. Neurol. 357, 65-75. doi: 10.1002/cne.903570107

Song, Y., Ori-McKenney, K. M., Zheng, Y., Han, C., Jan, L. Y., and Jan, Y. N. (2012). Regeneration of Drosophila sensory neuron axons and dendrites is regulated by the AKT pathway involving Pten and microRNA bantam. Genes Dev. 26, 1612-1625. doi: 10.1101/gad.193243.112

Sotelo, C., and Dusart, I. (2009). Intrinsic versus extrinsic determinants during the development of Purkinje cell dendrites. Neuroscience 162, 589-600. doi: 10.1016/j.neuroscience.2008.12.035

Stone, M. C., Albertson, R. M., Chen, L., and Rolls, M. M. (2014). Dendrite injury triggers DLK-independent regeneration. Cell Rep. 6, 247-253. doi: 10.1016/j. celrep.2013.12.022

Stone, M. C., Roegiers, F., and Rolls, M. M. (2008). Microtubules have opposite orientation in axons and dendrites of Drosophila neurons. Mol. Biol. Cell 19, 4122-4129. doi: 10.1091/mbc.e07-10-1079

Sun, A. X., Crabtree, G. R., and Yoo, A. S. (2013). MicroRNAs: regulations of neuronal fate. Curr. Opin. Cell Biol. 25, 215-221. doi: 10.1016/j.ceb.2012. 12.007

Szklarczyk, A., Lapinska, J., Rylski, M., McKay, R. D. G., and Kaczmarek, L. (2002). Matrix metalloproteinase-9 undergoes expression and activation during dendritic remodeling in adult hippocampus. J. Neurosci. 22, 920-930. doi: 10.1523/JNEUROSCI.22-03-00920.2002

Takahashi, S., Ishida, A., Kubo, A., Kawasaki, H., Ochiai, S., Nakayama, M., et al. (2019). Homeostatic pruning and activity of epidermal nerves are dysregulated in barrier-impaired skin during chronic itch development. Sci. Rep. 9:8625. doi: 10.1038/s41598-019-44866-0

Takeo, Y. H., Kakegawa, W., Miura, E., and Yuzaki, M. (2015). ROR $\alpha$ regulates multiple aspects of dendrite development in cerebellar Purkinje cells in vivo. J. Neurosci. 35, 12518-12534. doi: 10.1523/JNEUROSCI.007515.2015

Tao, J., and Rolls, M. M. (2011). Dendrites have a rapid program of injuryinduced degeneration that is molecularly distinct from developmental pruning. J. Neurosci. 31, 5398-5405. doi: 10.1523/JNEUROSCI.3826-10.2011

Tao, J., Feng, C., and Rolls, M. M. (2016). The microtubule-severing protein fidgetin acts after dendrite injury to promote their degeneration. J. Cell Sci. 129, 3274-3281. doi: $10.1242 /$ jcs. 188540

Terenzio, M., Koley, S., Samra, N., Rishal, I., Zhao, Q., Sahoo, P. K., et al. (2018). Locally translated mTOR controls axonal local translation in nerve injury. Science 359, 1416-1421. doi: 10.1126/science.an1053

Thompson-Peer, K. L., DeVault, L., Li, T., Jan, L. Y., and Jan, Y. N. (2016). In vivo dendrite regeneration after injury is different from dendrite development. Genes Dev. 30, 1776-1789. doi: 10.1101/gad.282848.116

Thummel, C. S. (2001). Molecular mechanisms of developmental timing in C. elegans and Drosophila. Dev. Cell 4, 453-465. doi: 10.1016/s15345807(01)00060-0

Togashi, K., Tsuji, M., Takeuchi, S., Nakahama, R., Koizumi, H., and Emoto, K. (2020). Adeno-associated virus-mediated single-cell labeling of mitral cells in the mouse olfactory bulb: insights into the developmental dynamics of dendrite remodeling. Front. Cell. Neurosci. 14:572256. doi: 10.3389/fncel.2020. 572256

Triplett, J. W., Owens, M. T., Yamada, J., Lemke, G., Cang, J., Stryker, M. P., et al. (2009). Retinal input instructs alignment of visual topographic maps. Cell 139, 175-185. doi: 10.1016/j.cell.2009.08.028

Tritsch, N. X., Yi, E. Y., Gale, J. E., Glowatzki, E., and Bergles, D. E. (2007). The origin of spontaneous activity in the developing auditory system. Nature 450, 50-55. doi: 10.1038/nature06233

Truman, J. W., and Reiss, S. E. (1976). Dendritic reorganization of an identified motoneuron during metamorphosis of the tobacco hornworm moth. Science 30, 477-479. doi: 10.1126/science. 1257782

Unsain, N., Higgins, J. M., Parker, K. N., Johnstone, A. D., and Barker, P. A. (2013). XIAP regulates caspase activity in degenerating axons. Cell Rep. 4, 751-763. doi: 10.1016/j.celrep.2013.07.015

Vonhoff, F., and Keshishian, H. (2017). In vivo calcium imaging during synaptic refinement at the Drosophila neuromuscular junction. J. Neurosci. 37, 5511-5526. doi: 10.1523/JNEUROSCI.2922-16.2017

Vonhoff, F., Kuehn, C., Blumenstock, S., Sanyal, S., and Duch, C. (2013). Temporal coherency between receptor expression, neural activity and AP-1-dependent transcription regulates Drosophila motoneuron dendrite development. Development 140, 606-616. doi: 10.1242/dev.089235

Wang, C.-F., Hsing, H.-W., Zhuang, Z.-H., Wen, M.-H., Chang, W.-J., Briz, C. G., et al. (2017). Lhx2 expression in postmitotic cortical neurons initiates assembly of the thalamocortical somatosensory circuit. Cell Rep. 18, 849-856. doi: 10.1016/j.celrep.2017.01.001

Wang, Y., Rui, M., Tang, Q., Bu, S., and Yu, F. (2019). Patronin governs minusend-out orientation of dendritic microtubules to promote dendrite pruning in Drosophila. eLife 8:e39964. doi: 10.7554/eLife.39964

Weiner, A. T., Seebold, D. Y., Torres-Gutierrez, P., Folker, C., Swope, R. D., Kothe, G. O., et al. (2020). Endosomal wnt signaling proteins control microtubule nucleation in dendrites. PLoS Biol. 18:e3000647. doi: 10.1371/journal.pbio.3000647

Williams, D. W., and Truman, J. W. (2005). Remodeling dendrites during insect metamorphosis. J. Neurobiol. 64, 24-33. doi: 10.1002/neu.20151

Williams, D. W., Kondo, S., Krzyzanowska, A., Hiromi, Y., and Truman, J. W. (2006). Local caspase activity directs engulfment of dendrites during pruning. Nat. Neurosci. 9, 1234-1236. doi: 10.1038/nn1774

Wong, R. O. L., and Ghosh, A. (2002). Activity-dependent regulation of dendritic growth and patterning. Nat. Rev. Neurosci. 3, 803-812. doi: 10.1038/ nrn941 
Wong, J. J., Li, S., Lim, E. K., Wang, Y., Wang, C., Zhang, H., et al. (2013). A Cullin1-based SCF E3 ubiquitin ligase targets the InR/PI3K/TOR pathway to regulate neuronal pruning. PLoS Biol. 11:e1001657. doi: 10.1371/journal.pbio. 1001657

Xiong, W. C., and Montell, C. (1993). Tramtrack is a transcriptional repressor required for cell fate determination in the Drosophila eye. Genes Dev. 7, 1085-1096. doi: 10.1101/gad.7.6.1085

Yamanaka, N., Rewitz, K. F., and O'Connor, M. B. (2013). Ecdysone control of developmental transition: lessons from Drosophila research. Annu. Rev. Entomol. 58, 497-516. doi: 10.1146/annurev-ento-120811-153608

Yang, J., Weimer, R. M., Kallop, D., Olsen, O., Wu, Z., Renier, N., et al. (2013). Regulation of axon degeneration after injury and in development by endogenous calpain inhibitor calpastatin. Neuron 80, 1175-1189. doi: 10.1016/j.neuron.2013.08.034

Yasunaga, K., Kanamori, T., Morikawa, R., Suzuki, E., and Emoto, K. (2010). Dendrite reshaping of adult Drosophila sensory neurons requires matrix metalloproteinase-mediated modification of the basement membranes. Dev. Cell. 18, 621-632. doi: 10.1016/j.devcel.2010.02.010

Yasunaga, K., Tezuka, A., Ishikawa, N., Dairyo, Y., Togashi, K., Koizumi, H., et al. (2015). Adult Drosophila sensory neurons specify dendrite territories independently of dendritic contacts through the Wnt5-Drl signaling pathway. Genes Dev. 29, 1763-1775. doi: 10.1101/gad.262592.115

Yong, V. W. (2005). Metalloproteinases: mediators of pathology and regeneration in the CNS. Nat. Rev. Neurosci. 6, 931-944. doi: 10.1038/nrn1807

Yu, F., and Schuldiner, O. (2014). Axon and dendrite pruning in Drosophila. Curr. Opin. Neurobiol. 27, 192-198. doi: 10.1016/j.conb.2014.04.005
Zhang, H., Wang, Y., Wong, J. J., Lim, K. L., Liou, Y. C., Wang, H., et al. (2014). Endocytic pathways downregulate the L1-type cell adhesion molecule Neuroglian to promote dendrite pruning in Drosophila. Dev. Cell 30, 463-478. doi: 10.1016/j.devcel.2014.06.014

Zhu, S., Chen, R., Soba, P., and Jan, Y.-N. (2019). JNK signaling coordinates with ecdysone signaling to promote pruning of Drosophila sensory neuron dendrites. Development 146:dev163592. doi: 10.1242/dev.163592

Zhu, T., Liang, X., Wang, X.-M., and Shen, K. (2017). Dynein and EFF-1 control dendrite morphology by regulating the localization pattern of SAX-7 in epidermal cells. J. Cell Sci. 130, 4063-4071. doi: 10.1242/jcs.201699

Zong, W., Wang, Y., Tang, Q., Zhang, H., and Yu, F. (2018). Prd1 associates with the clathrin adaptor $\alpha$-Adaptin and the kinesin-3 Imac/Unc-104 to govern dendrite pruning in Drosophila. PLoS Biol. 16:e2004506. doi: 10.1371/journal. pbio. 2004506

Conflict of Interest: The authors declare that the research was conducted in the absence of any commercial or financial relationships that could be construed as a potential conflict of interest.

Copyright (c) 2021 Furusawa and Emoto. This is an open-access article distributed under the terms of the Creative Commons Attribution License (CC BY). The use, distribution or reproduction in other forums is permitted, provided the original author(s) and the copyright owner(s) are credited and that the original publication in this journal is cited, in accordance with accepted academic practice. No use, distribution or reproduction is permitted which does not comply with these terms. 